\title{
Source Attribution and Risk Assessment of Antimicrobial Resistance
}

\author{
Pires, Sara Monteiro; Riberio Duarte, Ana Sofia; Hald, Tine
}

Published in:

Microbiology Spectrum

Link to article, DOI:

10.1128/microbiolspec.ARBA-0027-2017

Publication date:

2018

Document Version

Peer reviewed version

Link back to DTU Orbit

Citation (APA):

Pires, S. M., Riberio Duarte, A. S., \& Hald, T. (2018). Source Attribution and Risk Assessment of Antimicrobial Resistance. Microbiology Spectrum, 6(3), [ARBA-0027-2017]. https://doi.org/10.1128/microbiolspec.ARBA-00272017

\section{General rights}

Copyright and moral rights for the publications made accessible in the public portal are retained by the authors and/or other copyright owners and it is a condition of accessing publications that users recognise and abide by the legal requirements associated with these rights.

- Users may download and print one copy of any publication from the public portal for the purpose of private study or research.

- You may not further distribute the material or use it for any profit-making activity or commercial gain

- You may freely distribute the URL identifying the publication in the public portal 
1 Source Attribution Models and Risk Assessment

2 Sara M. Pires, Ana Sofia Duarte and Tine Hald

3

4 Sara M. Pires*

5 Risk Benefit Research Group, Division of Diet, Disease Prevention and Toxicology,

$6 \quad$ National Food Institute, Technical University of Denmark

7 Kemitorvet, Building 201, Room 116. 2800 Kgs. Lyngby

8 Phone: +4540213489

$9 \quad$ E-mail: smpi@ food.dtu.dk (SP)

10 ORCID: orcid.org/0000-0002-7751-1509

12 Ana Sofia R. Duarte

13 Unit for Genomic Epidemiology, National Food Institute, Technical University of Denmark

14 Kemitorvet, Building 204. 2800 Kgs. Lyngby

15 Phone: +4571701798

16 E-mail: asrd@food.dtu.dk (AD)

17 ORCID: orcid.org/0000-0002-8794-0542 
20 Unit for Genomic Epidemiology, National Food Institute, Technical University of Denmark

21 Kemitorvet, Building 204. 2800 Kgs. Lyngby

22 Phone: +4551157485

23 E-mail: tiha@ food.dtu.dk (TH)

24 ORCID: orcid.org/0000-0002-1115-9792

*Corresponding Author. Send proofs to:

27 Sara M. Pires, smpi@food.dtu.dk

\section{Summary}

29 Source attribution and microbial risk assessment methods have been widely applied for the

30 control of several foodborne pathogens worldwide by identifying i) the most important pathogen

31 sources, and ii) the risk represented by specific foods and the critical points in these foods'

32 production chain for microbial control. Such evidence has proved crucial for risk managers to

33 identify and prioritize effective food safety and public health strategies. In the context of

34 antimicrobial resistance (AMR) from livestock and pets, the utility of these methods is

35 recognized but a number of challenges have largely prevented their application and routine use.

36 One key challenge has been to define the hazard in question: is it the antimicrobial drug use in

37 animals, the antimicrobial resistant bacteria in animals and foods, or the antimicrobial resistant

38 genes that can be transferred between commensal and pathogenic bacteria in the animal or human

39 gut or in the environment? Other important limitations include the lack of occurrence and

40 transmission data, and the lack of evidence to inform dose-response relationships. We present the 
41 main principles, available methods, strengths and weaknesses of source attribution and risk

42 assessment methods, discuss their utility to identify sources and estimate risks of AMR from

43 livestock and pets, and provide an overview of conducted studies. In addition, we discuss

44 remaining challenges and current and future opportunities to improve methods and knowledge on

45 the sources and transmission routes of AMR from animals through food, direct contact or the

46 environment, including due to improvements in surveillance and developments on genotypic

47 typing methods.

$49 \quad$ 1. Introduction

50 Antimicrobial use in humans and animals has been identified as a main driver of AMR, and

51 bacteria harboring resistance to antimicrobials can be found in humans, animals, foods and the

52 environment. As a consequence, humans can be exposed to antimicrobial resistantbacteria

53 through a wide range of sources and transmission pathways. To inform policies aimed at

54 reducing the burden of AMR from animals and foods, risk managers need evidence on the most

55 important sources and transmission routes, and the critical points throughout the production chain

56 for the prevention and control of AMR. While this process is complex and deeply reliant on the

57 integration of surveillance data from humans, animals and foods, it is supported by scientific

58 disciplines that have evolved rapidly in the last decades, including source attribution and

59 quantitative risk assessment.

60 Source attribution is a relatively new discipline that has been developed to assist risk managers to

61 identify and prioritize effective food safety intervention measures. It is defined as the partitioning

62 of the human disease burden of one or more foodborne illnesses to specific sources, where the 
term source includes reservoirs and vehicles (1). A variety of source attribution methods is

64 available to estimate the relative contribution of different reservoirs or vehicles of foodborne

65 pathogens, including methods relying on data on the occurrence of the pathogen in sources and

66 humans, epidemiological studies, intervention studies or expert elicitations. These methods have

67 been applied to inform food safety policy-making at national or international level, particularly to

68 inform Salmonella and Campylobacter intervention strategies (see e.g. (2-6)). Source attribution

69 methods differ in their approaches and data requirements, and as a consequence they attribute

70 disease at different points along the food chain (points of attribution), i.e. at the point of reservoir

71 (e.g. animal production stage, environment emissions) or point of exposure (end of the

72 transmission chain) (Figure 1). The application and utility of each method, therefore, depends on

73 the risk management question being addressed and on the availability of data.

75 Figure 1. Routes of transmission of zoonotic pathogens and points of source attribution. Adapted 76 from (7).

77 Microbial risk assessment is a systematic and science-based approach to estimate the risk of 78 microbial hazards in the production-to-consumption chain $(8,9)$. Microbial risk assessment can

79 be used to detect critical control points along the food chain and for the assessment of control and 80 intervention strategies. It is a well-established discipline that has been widely applied to estimate 81 the risk of an extensive variety of pathogen-food commodity pairs, and it is also systematically

82 applied to inform food safety risk management in many countries and international bodies such

83 as the European Food Safety Authority (EFSA) (e.g. (10-12)). In coordination with source

84 attribution studies, it is particularly useful to focus on the production chain of the most important

85 source(s) of the hazard of interest (as identified in the source attribution step), identify the steps 
86 in the food chain that are critical for hazard control, and identify and suggest strategies for

87 reduction of the risk to humans.

88 While source attribution and risk assessment have been widely used to provide evidence that can

89 support strategies to reduce the burden of a number of foodborne pathogens, the transmission and

90 spread of pathogens carrying resistance to antimicrobials adds an extra layer of complexity to this

91 integrated food safety paradigm. On one hand, virtually any foodborne pathogen can acquire

92 resistance to antimicrobials, which may lead to prolonged and more severe disease and even be

93 life-threatening, when antimicrobial therapy is required but fails to succeed due to resistance

94 towards the prescribed $\operatorname{drug}(\mathrm{s})$. On the other hand, the potential transfer of antimicrobial

95 resistance genes (i.e. the gene(s) carrying the resistance trait) between pathogenic and commensal

96 bacteria in the human gut can amplify the public health impact of foodborne AMR (13). As a

97 consequence, it is not only challenging to estimate the direct risk posed by resistant foodborne

98 pathogens, but also to quantify the relative contribution to risk of the transfer of AMR genes, e.g.

99 from commensals originating from animal reservoirs to human pathogens.

100 This chapter describes the overall concepts and methods within source attribution and microbial

101 risk assessment, provides the state-of-the art of their application in the area of AMR, and

102 discusses current challenges and future perspectives for the development of methods to inform

103 policies to reduce the disease burden of AMR in human populations.

\section{2. Source attribution}

$105 \quad$ 2.1. Source attribution of antimicrobial resistance

106 The purpose of applying source attribution methods to antimicrobial resistant pathogens (i.e. a

107 pathogen that has acquired resistance to at least one antimicrobial drug) or AMR genes is to 
identify the most important sources and transmission routes for human exposure to AMR. It is

109 widely recognized that one of the main drivers of resistance in zoonotic bacteria is antimicrobial 110 use in livestock production (i.e. in the reservoirs) (14). Identifying the most important reservoirs

111 for human exposure to AMR is hence critical to direct policy making aimed at reducing

112 antimicrobial use at the primary production level. In addition, knowledge on the transmission

113 routes from reservoirs to humans is crucial for the prioritization of risk management along the

114 food chain.

115 While a range of source attribution methods attributing disease to the original reservoirs or to 116 exposure routes of foodborne pathogens exists, only a few studies have applied these in the 117 context of AMR, and the relative importance of transmission pathways of resistance remains a 118 critical knowledge gap.

119 Challenges of applying source attribution methods for AMR include the fact that virtually any 120 pathogen can become resistant to antimicrobials and that most zoonotic pathogens can be 121 transmitted to humans via a variety of foodborne and non-foodborne routes. Thus far, source 122 attribution typically focused on a single pathogen (e.g. Salmonella or Escherichia coli), and on 123 resistance profiles found among that pathogen in different sources (15-17). In addition, 124 antimicrobial resistance genes are often located on plasmids, which can be transferred between 125 bacterial species (plasmid-mediated horizontal gene transfer) and therefore also from commensal 126 bacteria to human pathogens (e.g. Klebsiella spp.). Focusing on a single bacterial species is 127 therefore likely to underestimate the overall exposure and thus the risk posed by AMR.

128 To address this challenge, source attribution of the AMR determinant may be more efficient. 129 Such studies require knowledge and data on the prevalence, abundance and transmission of 130 genes, and on horizontal gene transfer rates, which is still being gathered (e.g. in the European 
131 Union project EFFORT - Ecology from Farm to Fork Of microbial drug Resistance and

132 Transmission; http://www.effort-against-amr.eu/).

$133 \quad$ 2.2. Existing source attribution approaches

\subsubsection{Microbial subtyping}

135 The microbial subtyping approach involves characterization of the hazard by subtyping methods

136 (e.g., phenotypic or genotypic subtyping of bacterial strains), and the principle is to compare the 137 subtypes of isolates from different sources (e.g. animals, food) with the subtypes isolated from 138 humans. The subtyping approach attributes illness at the point of reservoir and is enabled by the 139 identification of strong associations between some of the dominant subtypes and a specific 140 reservoir or source, providing a heterogeneous distribution of subtypes among the sources (1).

141 Microbial subtyping methods for source attribution include frequency matched models and 142 population genetic models. While the frequency matched methods are based on the comparison 143 of human strain types and the distribution of those types in the sources, the population genetic 144 models are based on modelling the organism's evolutionary history (18). In the frequency145 matched models, subtypes exclusively or almost exclusively isolated from one source are 146 regarded as indicators for the human health impact of that particular source, assuming that all 147 human cases caused by these subtypes originate only from that source. Human cases of disease 148 caused by subtypes found in several reservoirs are then distributed relative to the prevalence of 149 the indicator types $(2,3,19)$. Population genetics approaches use genotyping data to infer 150 evolutionary and clonal relationships among different strains, including the occurrence of novel 151 (combinations of) alleles in strains from humans that are unobserved in source populations (20). 
152 All microbial subtyping models require a collection of temporally and spatially related isolates

153 from various sources, and thus are facilitated by an integrated foodborne disease surveillance

154 programme providing a collection of isolates from the major animal reservoirs of foodborne

155 diseases. These models do not require prevalence data, and can rely on the distribution of the

156 isolates' subtypes in the different sources and in humans.

157 Either type of models has been applied to attribute foodborne pathogens to sources in a variety of

158 countries. Microbial subtyping approaches have been particularly successful to attribute

159 Salmonella and Campylobacter infections (see e.g. (3, 21-24)). The method has also been

160 applied to other pathogens (namely Listeria monocytogenes and shiga toxin-producing

161 Escherichia coli $(25,26))$, even though less frequently due to lack of available surveillance data

162 in most countries.

163 The microbial subtyping approach has seldom been used to estimate the relative contribution of

164 sources of antimicrobial resistant pathogens to AMR in humans. To our knowledge, two

165 frequency-matched studies have been conducted, both using antimicrobial susceptibility patterns

166 as a typing method for Salmonella $(15,16)$. Both studies demonstrate that AMR data can be used

167 to characterize pathogen subtypes in a microbial subtyping source-attribution model, and discuss

168 its utility in terms of discriminatory power, but do not focus on the source origin of specific AMR

169 genes.

170 Microbial subtyping methods are recognized as one of the most robust data-driven methods for

171 source attribution. They have the advantage of attributing illness to the reservoirs of the

172 pathogens, thus informing risk-management strategies closest possible to the original sources and

173 preventing further spread to other routes or sources of transmission (1). Another advantage of this

174 approach is that it does not require data on the prevalence and concentration of the pathogen in 
175 the different sources (which is often difficult to obtain), or on the exposure frequency in the

176 population. Still, these methods are often limited by the requirement of comparable subtyping

177 data originating from an operative integrated surveillance of human cases and food/animals. In

178 addition, the methods cannot distinguish between different transmission routes from a specific

179 animal reservoir to humans.

\subsubsection{Comparative exposure assessment}

181 Comparative exposure assessments determine the relative importance of the known transmission

182 routes by estimating the human exposure to the hazard (e.g. pathogen) via each route. For each

183 known transmission route, this approach requires information on the prevalence and/or

184 dose/concentration of the pathogen in the source, of the changes of the prevalence and quantity of

185 the pathogen throughout the transmission chain, and of the frequency at which humans are

186 exposed by that route (e.g. consumption data). Exposure doses are then compared, and the

187 relative contribution of each of the various transmission routes to human exposure in the

188 population is estimated, proportionally to the size of each exposure dose.

189 The data requirements of the comparative exposure assessment approach will depend on the

190 overall transmission groups considered in the model (i.e. foodborne, environmental and/or

191 contact with animals), as well as on the point in the transmission chain where the "origin" of the

192 pathogen is set. In general, contamination data for each source, information on the main steps in

193 the transmission chain and data on the effects of these on contamination, and exposure data are

194 needed. If transmission via contact with live animals is considered, the exposure model needs to

195 be expanded and consider different possibilities for direct and indirect contact with a

196 contaminated animal. 
197 Exposure assessments have been used with different degrees of success to source attribute disease 198 by several microbial agents, namely Listeria, Campylobacter, VTEC (and Toxoplasma gondii, 199 and by chemical hazards - aflatoxins, cadmium and lead(27-34).

200 In the context of AMR, this approach is particularly useful to address a widely-recognized 201 knowledge gap, which is understanding the relative contribution of the exposure routes of AMR 202 from animals to humans. Specifically, it can be used to estimate the relative importance of the 203 food chain, companion animals and the environment for exposure of the general population to 204 antimicrobial resistant bacteria or AMR genes. Thus far (and to our knowledge), two comparative 205 exposure assessments have been applied to estimate the relative contribution of different types of 206 meat to the exposure of consumers to extended spectrum beta-lactamases (ESBL)/and AmpC 207 beta-lactamases producing Escherichia coli in the Netherlands(17) and in Denmark (35).

208 An important drawback of this approach is that, due to data limitations and gaps (e.g. in food 209 preparation habits and the effect of these in the contamination of foods), exposure estimates for 210 microbial pathogens are likely to present wide uncertainty intervals. Furthermore, in the context 211 of AMR, these studies focus on specific antimicrobial resistant pathogens, and do not address all 212 concomitant transmission routes contributing to overall transmission of resistance to humans (e.g. 213 same AMR determinant present in other members of the meat bacterial community), which adds 214 to the uncertainty of the relative exposure estimates.

\subsubsection{Epidemiological approaches}

216 Epidemiological approaches for source attribution include analyses of data from outbreak 217 investigations and studies of sporadic infections; both approaches attribute illness at the point of 218 exposure. An outbreak is here defined as (1) the occurrence of two or more cases of a similar 
219 illness resulting from the exposure to a common source (36), or (2) a situation in which the

220 observed number of cases exceeds the expected number and where the cases are linked to the

221 same food source (37). Sporadic cases represent cases that have not been associated with known

222 outbreaks (38). Even though outbreak-associated cases are more likely to be captured by public

223 health surveillance systems, an unknown proportion of cases classified as sporadic may be part of

224 undetected outbreaks.

225 Many outbreak investigations are successful in identifying the specific contaminated source or

226 ingredient causing human infections. A simple descriptive analysis or summary of outbreak

227 investigations is useful for quantifying the relative contribution of different foods to outbreak

228 illnesses. However, these implicated foods may be composed of multiple ingredients, and thus

229 outbreak data does not always allow pinpointing the actual source of infection. Probabilistic

230 models using outbreak data to estimate the total number of illnesses in the population attributable

231 to different foods provide a useful way to generalize outbreak data to a broader population of

232 foodborne illnesses. These models are not only used to generalize the results of outbreak

233 investigations, but also to estimate the contaminated sources in composite or "complex" foods.

234 Analyses of data from outbreak investigations benefit from detailed data on each reported

235 outbreak, and require the adoption of a food categorization scheme for classification of

236 implicated foods (see e.g.(39)). Composite foods will be assigned to two or more food categories

237 depending on the number and nature of their ingredients. By assigning a probability to each

238 ingredient corresponding to the likelihood that it was the source of the outbreak, outbreak data,

239 including data about both simple and complex foods, can be used to attribute foodborne illnesses

240 to sources. 
241 Several analyses of outbreak data for source attribution have been published in recent years, most 242 of them modelling $(40-42)$ or summarizing $(43,44)$ data from multiple pathogens. The strength

243 of this method is that it uses data that is readily available in many countries worldwide, and thus

244 its use is not restricted to countries with integrated foodborne disease surveillance programmes.

245 Also, it attributes foodborne illnesses at the point of exposure, which means that it is particularly

246 useful to identify which foods (including processed foods) most frequently cause disease, as well

247 as which risk factors contribute more for contamination of foods at the end of the food chain (e.g.

248 cross contamination). This type of information is valuable to define interventions at the

249 processing and consumption level, but does not provide evidence to inform risk management

250 strategies at the origin of the pathogen (reservoirs).

251 Several outbreaks caused by antimicrobial resistant pathogens have been reported and

252 investigated in the last decades (see e.g. $(45,46)$ ). A review of outbreak data has also been used

253 for source attribution of antimicrobial resistant Salmonella in the United States, suggesting that

254 antimicrobial susceptibility data on isolates from foodborne outbreaks can help determine which

255 foods are associated with resistant infections (47). Even though few countries or regions are

256 likely to have sufficient data for a robust source attribution analysis using AMR-related

257 outbreaks, summarizing available information may provide evidence on the relative contribution

258 of different foods for infection with antimicrobial resistant pathogens.

259 Another epidemiological approach that can be used for source attribution of foodborne disease is

260 the case control study of sporadic cases. Case-control studies are a valuable tool to identify

261 potential risk factors for human illness, including sources and predisposing, behavioral or

262 seasonal factors (48). In addition to individual case-control studies, a systematic review of

263 published case-control studies of sporadic infections of a given pathogen can provide an 
264 overview of the relevant exposures and risk factors for that disease, and a summary of the

265 estimated population attributable fractions for each exposure (49). A systematic review follows a 266 rigorous search strategy to identify all potentially relevant peer-review case-control studies for a

267 hazard, studies being conducted in a variety of countries and time periods, designed with

268 different settings, and potentially focused on specific age groups within the population. A meta-

269 analysis is then performed to compare and combine information from different studies. To do

270 this, risk factors may be stratified according to source-categorization schemes, location of

271 exposures and, if appropriate, frequency of exposure. An overall population attributable fraction

272 derived from a meta-analysis or weighted summary of several case-control studies of a certain

273 hazard can be combined with estimates of the burden of disease caused by that hazard to estimate

274 the burden of disease attributed to each exposure.

275 This method is particularly useful for hazards that do not frequently cause outbreaks but that have

276 been extensively studied (50). In addition, it is valuable to attribute illness at a regional or global

277 level when data are scarce in most countries. A number of case-control studies have been

278 conducted to investigate risk factors for infection with foodborne pathogens resistant to

279 antimicrobials (see e.g. $(51,52)$ ). However, the utility of a meta-analysis of case-control studies

280 to investigate the relative contribution of different sources and risk factors for infection with

281 antimicrobial resistant pathogens may be limited if a low number of case-control studies focused

282 on specific antimicrobial resistant pathogens or AMR genes has been conducted.

284 Other approaches for source attribution of foodborne pathogens include intervention studies and 285 expert elicitations. Intervention studies are large-scale, well-structured prospective studies that 
are specifically tailored to evaluate direct impacts of a specific intervention on the risk of disease

287 in a population. While they would be the gold-standard of an attribution study, they have the

288 disadvantages of being resource-demanding, expensive, and difficult to implement because other

289 concurrent factors may affect occurrence of disease.

290 Expert elicitations can be designed as structured methods to gather and analyze knowledge from

291 experts, which are communicated with a measure of uncertainty. They are particularly useful to

292 attribute the burden of foodborne diseases to main transmission pathways (i.e. foodborne,

293 environmental, direct contact), for which data-driven methods are typically insufficient(50).

294 There are numerous methods used for expert elicitation, including methods that are based upon

295 iteration and finding consensus among a small group of experts (e.g. the Delphi method). Expert

296 judgments are subjective by nature and may be biased by the specific background and scientific

297 expertise of the respondents, and several methods to evaluate the expert's performance have been

298 described. Several expert elicitation studies have been conducted for source attribution of

299 foodborne disease (e.g. Havelaar et al. 2008; Ravel et al. 2010). The World Health Organization's

300 Initiative to Estimate the Global Burden of Foodborne Diseases (WHO-FERG) has undertaken a

301 large-scale and successful expert elicitation to attribute disease by 19 foodborne hazards to main

302 transmission groups at a global, regional and sub-regional level (55). The study applied

303 structured expert judgment using Cooke's Classical Model (56) to obtain estimates for the

304 relative contributions of different transmission pathways for several foodborne hazards.

\section{$305 \quad$ 2.3. Applications and results}

306 Despite the increased recognition of the importance of source attribution of foodborne pathogens 307 to direct risk management strategies, and the growing use of these approaches in several countries 
and research groups, source attribution of AMR is still in its infancy. There are few published

309 examples of the different methods here described, and the identified challenges are still being

310 addressed. The two microbial subtyping studies published are both frequency-matched studies

311 that used antimicrobial susceptibility patterns as a typing method for Salmonella $(15,16)$. These

312 studies use AMR profiles as a typing method (i.e. to characterize pathogen subtypes) but do not

313 focus on the source origin of specific AMR genes. Still, they are able to estimate the distribution

314 of AMR in human cases attributed to different sources, as is done routinely in the Salmonella

315 source attribution activities in Denmark (57). Similarly, the two comparative exposure

316 assessments that have been applied to estimate the relative contribution of different types of meat

317 to the exposure of consumers to AMR have focused on the same causative agent, this time

318 extended spectrum beta-lactamases (ESBL)/and AmpC beta-lactamases producing Escherichia

319 coli $(17,35)$. These studies demonstrate that the method could be extended to other countries and

320 agents. The recent review of outbreak data for source attribution of antimicrobial resistant

321 Salmonella in the United States suggests that antimicrobial susceptibility data on isolates from

322 foodborne outbreaks can help determine which foods are associated with resistant infections (47).

323 This method could be applied in countries that have sufficient data, or to regional data in an

324 attempt to gather information from multiple countries. Numerous epidemiological studies of

325 sporadic infections (case-control or cohort studies) investigating risk factors for of antimicrobial

326 resistant infections in humans demonstrate these methods usefulness to identify routes of AMR

327 (e.g. (58-60). While their use focusing on foodborne or direct or indirect contact to animals'

328 transmission has been limited, available studies still provide information for food safety risk

329 management $(51,52)$. 
331 Source attribution of AMR genes and of antimicrobial resistant pathogens is a research area

332 under active development. The application of the methods here described remains a challenge, for 333 reasons that depend on each method considered.

334 For the application of subtyping frequency-matched studies, two of the main challenges are the 335 limited availability of animal, food and human AMR data from established surveillance systems, 336 and the difficulty to define number of antimicrobial resistance profiles highly specific to a 337 particular source/transmission route, a cornerstone of this method. Furthermore, the fact that the 338 method does not determine the actual transmission route from each specific reservoir to humans 339 represents another limitation for the use of frequency-matched models. Due to the public health 340 need for understanding the transmission of AMR, population genetics approaches may eventually

341 be a good complement to frequency-matched models, especially considering the increasing 342 availability of whole genome sequencing and metagenomics data, which describe occurrence of 343 AMR genes in populations. For instance, population genetics can help identifying reservoir344 specific AMR genes' patterns that can then be used in frequency-matched models. New 345 generation sequencing data may also contribute to unravel details that contribute to a more 346 accurate source-attribution, such as the evolution of AMR patterns over time in different sources, 347 and resistance in humans that is not transmitted from animals or foods.

348 While single genomics and metagenomics may support the development of novel subtyping 349 source-attribution methods, they may hinder the application of comparative exposure assessment. 350 Information on prevalence and quantity of AMR genes or antimicrobial resistant pathogens in 351 each source, as well as their changes throughout the transmission chain, are difficult to assess 352 from those data and impaired by a high degree of uncertainty. 
353 Epidemiological methods of source-attribution, e.g. based on outbreak investigation, have the 354 advantage of not relying on a sophisticated, data abundant and integrated surveillance system, 355 encompassing animal reservoirs, foods and humans. However, they require consistent AMR 356 investigation on food sources and human cases, based at least on bacterial isolation and 357 phenotypic susceptibility testing. Eventually, new generation sequencing may overtake 358 traditional diagnostic methods in outbreak investigation $(14,61)$, which will also require 359 modification of the current epidemiological approaches.

360 Intervention studies have, in the context of AMR, the same limitations as when applied to 361 bacterial pathogens. It is difficult to evaluate the exact impact of a specific intervention (e.g. 362 reducing antimicrobial use at the farm level) on the population where disease is attributed (e.g. 363 AMR occurrence in humans). Control measures that reduced antimicrobial use in primary 364 production have been successfully implemented with the aim of reducing AMR in animals (e.g. 365 the antimicrobial growth promoter intervention, the voluntary ban on the use of cephalosporins 366 and the yellow card antimicrobial scheme in swine herds in Denmark (62-64)). However, to 367 assess the real success of such measures in terms of public health impact, it is necessary to collect 368 data prior to and following the intervention (14), at all dimensions of AMR transmission to 369 humans, i.e. also including other transmission routes such as environment and antimicrobial use 370 in humans. 


\section{3.1. Microbial Risk Assessment (MRA) of antimicrobial resistance}

374 Risk assessment is the process of estimating the likelihood that exposure to a biological, chemical 375 or physical hazard will result in an adverse health effect in exposed individuals. Microbial risk 376 assessment has been established as a part of the food safety risk analysis paradigm by

377 international and national bodies in the last decades, with harmonized guidelines being proposed 378 and widely adopted worldwide $(8,65)$. In the context of AMR, risk assessments are useful to 379 inform regulatory decision making for the mitigation of potential health consequences in both 380 humans and animals (66). While the importance and need for AMR risk assessments have been 381 recognized for decades (67), its application has been complicated by several knowledge gaps. 382 Challenges of the development of AMR risk assessment include:

$383-$ The nature of the hazard is difficult to identify and will determine the nature of the adverse consequence of the exposure. In the context of AMR risk assessment, different hazards can be considered (68, 69). For example, Salisbury et al.(2017) (68)discussed three interrelated hazards that can be assessed separately: the antimicrobial drug, the antimicrobial resistantbacteria, and the AMR determinant, leading to three different health consequences, respectively - development of resistance, infection and treatment failure and transference of resistance. Similarly, Manaia (2017)(69) describes that resistomeassociated risks have been discussed considering the microbial community, the genome and transmission of resistance. complex and logically linked to the nature of the hazard, as mentioned above. In other words, while the likelihood that humans will be infected by pathogens that are resistant to 
one or several antimicrobials can be estimated, the resulting adverse health consequences can be one or several of the following: development of disease due to infection with the pathogen; failure of treatment of the infection due to resistance to the used drug(s); and risk and extend the impact of an isolated exposure in time).

- There are numerous factors in the process of selection and spread of resistance in bacterial populations, between and within animal species, humans and the environment, and within different bacterial populations in those same reservoirs. These factors include the several drivers for the emergence and spread of AMR in the food production, specifically at the farm. At this level, antimicrobial use is recognized as the most important driver, but not always necessary (if for example co-resistance and co-selection occur), and not always sufficient; additional drivers are e.g. poor prevention and control of infectious diseases leading to increased antimicrobial use and the spread of clones that have established themselves in the herd/environment, and keep selective pressure, even if antimicrobial use is interrupted. These factors, among many others, influence the development of exposure assessment in microbial risk assessment.

- Additionally to the challenges described above, estimating the likelihood of adverse health effects, given exposure to an antimicrobial resistant pathogen or determinant, is difficult due to the absence of a well-defined dose-response effect for AMR, and the

415 Recognizing the need for AMR risk assessments to identify strategies aimed at preventing and 416 reducing the disease burden of AMR transmitted through foods, a number of reviews and 417 scientific articles have proposed frameworks for such risk assessments in the late 90's and early 
4182000 's $(67,68,70)$. Even though such proposals were comprehensive and structured to address

419 the challenges identified at that time, they were not widely adopted, mostly due to remaining

420 knowledge and data gaps in the AMR transmission and impact. More recent frameworks apply

421 current available data and either are mostly qualitative or semi-quantitative (see e.g. $(71,72)$ ),

422 take a linear approach (e.g. (73)), and/or focus on marketing authorization applications for

423 antimicrobial veterinary medicinal products for use in food producing species (74).

425 3.2. Description of the four steps of microbial risk assessment focusing on AMR

426 The microbial risk assessment process is, as described by the Codex Alimentarius guidelines (8),

427 constituted by four main components: hazard identification, hazard characterization, exposure

428 assessment and risk characterization.

429 In an AMR risk assessment, the hazard can be the antimicrobial drug, the antimicrobial resistant

430 pathogen or the AMR determinant. Ultimately, the identification of the hazard of interest will

431 depend of the risk-assessment question to be addressed. In a traditional microbial risk assessment

432 (i.e. focused on a pathogen-food pair, without considering resistance to antimicrobial drugs) the

433 hazard identification step consists of the qualitative description of the hazard, including the

434 evaluation of the presence of the pathogen in a food product available for consumption in a

435 population and the host interface (types of disease caused, susceptible populations). In the context

436 of AMR, this step is complicated by a number of factors: i) selection of resistance in a pathogen

437 can occur by multiple mechanisms (namely mutation and horizontal gene transfer of mobile

438 genetic elements containing AMR genes (HGT)) (75); ii) one or more genes may be necessary for

439 development of AMR; iii) AMR genes can be located in chromosomal or extra-chromossomal 
440 DNA such as plasmids (75), and iv) several bacterial species or strains can harbor and serve as a 441 reservoir for resistance.

442 The hazard characterization step of a risk assessment consists of the review and collection of 443 information on the relationship between the dose of the hazard and the onset of disease in the 444 exposed individuals (i.e. infectious dose), and the relationship between different doses and the 445 probability of occurrence of disease (i.e. dose-response). The response of a human population to 446 exposure to a foodborne pathogen is highly variable, reflecting the fact that the incidence of 447 disease is dependent on a variety of factors such as the virulence characteristics of the pathogen, 448 the numbers of cells ingested, the general health and immune status of the hosts, and the 449 attributes of the food that alter microbial-host interaction (76). Thus, the likelihood that any 450 individual becomes ill due to an exposure to a foodborne pathogen is dependent on the 451 integration of host, pathogen, and food matrix effects. Again, in AMR risk assessment, the 452 required data to assess a dose-response relationship will depend on the hazard considered; it can 453 be one of the three: dose level of the antimicrobial for observing resistance usually expressed by 454 minimum inhibitory concentration (MIC) breakpoint (75), or any other factor that can affect the 455 development or amplification of resistance, the dose of the pathogen needed to cause disease, or 456 any factor related to the stability and transfer potential of the AMR gene in a bacterial population 457 (68).

458 In the exposure assessment step, the likelihood that an individual or a population will be exposed 459 to a hazard and the numbers of the microorganism that are likely to be ingested are estimated 460 (77). The exposure assessment requires data on the prevalence and concentration of the hazard in 461 the food source(s), as well as information on the potential changes of the pathogen load 462 throughout the food processing chain (e.g. growth, reduction) (78); in addition, it requires data on 
463 the frequency and amount of food consumed by individuals of the population. As mentioned

464 above, numerous factors influence the process of selection and spread of resistance, consequently

465 influencing the final exposure of the consumer to AMR genes or antimicrobial resistant

466 pathogens. These factors are either still unknown or there are limited data reporting their

467 influence on AMR transmission throughout the food chain.

468 In the last component of a risk assessment, risk characterization, the final risk to the consumer is

469 estimated by integrating the previous three components. Specifically, the measure of exposure

470 (i.e. the likely dose an individual is exposed to in a given food consumption/exposure event) is

471 integrated with the dose-response relationship to estimate the likelihood of adverse health effect.

472 In the context of AMR microbial risk assessment, even after an appropriate definition of the risk

473 question and the targeted hazard identification (which determine the adverse effect to be

474 assessed), and the estimation of the likelihood of exposure to the hazard of interest,

475 characterizing the risk in the absence of an appropriate and comprehensive hazard

476 characterization step remains a challenge. A "dose-response" step becomes particularly

477 demanding when "dose" at exposure is expressed in genotypic terms (by use of genomics or

478 metagenomics AMR data) and "response" must be expressed in phenotypic terms (e.g.

479 expression of resistance in a pathogen or horizontal transfer of an AMR gene between

480 commensal and pathogenic bacteria).

$481 \quad$ 3.3. $\quad$ Applications and results

482 A number of risk assessments focused on specific antimicrobial resistant pathogens-food/animal 483 pairs have been conducted since the publication of the different proposed guidelines. These 484 include qualitative, semi-quantitative and quantitative risk assessments, performed by food 
authorities, academia or industry. Here we provide examples of the three-types of risk assessment

486 that have been important to highlight the challenges and limitations they still face, the

487 applications of their results and the need for further studies.

\section{Qualitative risk assessments}

489 One of the first studies published assessed the health impact of residues of antibacterial and anti490 parasitic drugs in foods of animal origin and was published over two decades ago (79). It was a 491 qualitative and comprehensive review that focused on residues of a variety of drugs in multiple 492 foods, and an important step for the recognition of several of the challenges described in this 493 chapter. More drug- and pathogen-focused qualitative assessments have been conducted since 494 then, including in recent years, such as the qualitative risk assessment focused on Methicillin 495 resistant Staphylococcus aureus (MRSA) conducted by a multi-sectorial and interdisciplinary 496 expert group in Denmark (80). This study is a good example of an applied risk assessment, 497 conducted upon request from the food and veterinary authorities with the aims of 1) assessing the 498 risk of livestock MRSA based on the existing knowledge and the results of veterinary screening 499 studies conducted in herds, and 2) providing recommendation for control measures to reduce the 500 spread of MRSA from the affected herds to the surrounding environment and community. The 501 method consisted of a comprehensive evaluation of all available data on the prevalence of MRSA 502 in animals and humans, as well as on the risk factors for infection by livestock MRSA from the 503 environment, from meat, from occupational activities (e.g. risk for slaughterhouse or farm 504 workers) and from the community. The risk assessment consisted of a descriptive evaluation of 505 the risk of these types of transmission in the Danish population.

506 Another recent study has applied the risk assessment framework developed by the European 507 Medicines Agency (74) to assess the AMR risk to public health due to use of antimicrobials in 
508 pigs, using pleuromutilins as an example (81). Livestock-associated methicillin-resistant

509 Staphylococcus aureus of clonal complex 398 (MRSA CC398) and enterococci were identified as 510 relevant hazards. This framework followed the International Organization for Animal Health's

511 (OIE) approach to risk assessment and consisted of four steps describing the risk pathway, 512 combined into a risk estimate. The study applied a qualitative approach, where the output of each

513 step was defined in a scale. Likewise, the level of uncertainty was described qualitatively in the

514 different steps and the output (as high, medium or low). The authors discuss the value of

515 mathematical modeling as a tool to simulate pathways and identifying ways of reducing

516 resistance. Still, they stress that the relationship between reducing consumption of antibiotics and

517 reducing resistance is not necessarily linear, and defend that this relationship needs to be better

518 established for modeling to have full value (81). Despite the fact that this study is recent at the

519 point of writing of this chapter and thus could build on all newly available evidence on AMR

520 mechanisms, it still dealt with substantial data and knowledge gaps that enhanced uncertainty

521 around outputs (81).

522 Another example of a qualitative assessment is the WHO's list of Critically Important

523 Antimicrobials (71). The list applies criteria to rank antimicrobials according to their relative

524 importance in human medicine. The purpose of this assessment is to provide clinicians,

525 regulatory agencies, policy-makers and other stakeholders' information to develop risk

526 management strategies for the use of antimicrobials in food production animals globally. The first

527 WHO list of Critically Important Antimicrobials was developed in a WHO expert meeting in 528 2005, where participants considered the list of all antimicrobial classes used in human medicine

529 and categorized antimicrobials into three groups of critically important, highly important, and 530 important based on two criteria that describe first the availability or not of alternatives to the 
531 antimicrobial for treatment of serious bacterial infections in people, and second if the

532 antimicrobial is used to treat infections by (1) bacteria that may be transmitted to humans from

533 nonhuman sources, or (2) bacteria that may acquire resistance genes from nonhuman sources.

534 The output of the qualitative assessment is a list of classes of drugs that met all three of a set of

535 defined priorities. Since its original publication, the assessment has been revised several times

536 and is now in its 5th edition.

537

Semi-quantitative risk assessments

538 One example of a semi-quantitative assessment is the study integrating a probabilistic

539 quantitative risk assessment conducted in Denmark to assess the human health risk of macrolide-

540 resistant Campylobacter infection associated with the use of macrolides in Danish pig production

541 (82). This model was able to account for exposure through imported and domestic meat (i.e. that

542 could be a vehicle for antimicrobial resistant bacteria as a consequence of antimicrobial drug use

543 in animal production in the country) and used evidence available at the time. One important

544 feature of this study is that, while it measured exposure probabilistically and thus reflected model

545 and data uncertainty, the final step of the risk assessment -risk characterization - used an ordinal

546 scale and thus risk was described in a qualitative scale.

Quantitative risk assessments

548 Several quantitative risk assessments have been published since the early 2000's. These include

549 the high profile assessment of fluoroquinolone-resistant Campylobacter from chicken in the

550 United States (US) (83), which ultimately prompted the Food and Drug Administration to

551 propose withdrawal of the approval of the new animal drug applications for fluoroquinolone use 
552 in poultry, an action that would prohibit fluoroquinolone use in chickens and turkeys in the 553 country (84).

554 Another early study employed probabilistic methodology to analyze the potential public health 555 risk from Campylobacter jejuni and fluoroquinolone-resistant $C$. jejuni due to fresh beef and 556 ground beef consumption (85). The model focused on the beef product at retail and modelled 557 consumer handling in the kitchen, processing and consumption. The model estimated first the 558 risk of Campylobacter infection through consumption of beef, and then the risk of treatment 559 failure given infection, concluding an increased health impact due to resistance.

560 In another study, a risk assessment followed the US Food and Drug Administration's Center for 561 Veterinary Medicine Guidance (86) and was commissioned by a pharmaceutical company to 562 estimate the risk of human infection treatment failure associated with the use of an AM drug in 563 food animals (87). The deterministic model included all uses of two macrolides in poultry, swine, 564 and beef cattle. The hazard was defined as illness (i) caused by foodborne bacteria with a 565 resistance determinant, (ii) attributed to a specified animal-derived meat commodity, and (iii) 566 treated with a human use drug of the same class. Risk was defined as the probability of this 567 hazard combined with the consequence of treatment failure due to resistant Campylobacter spp. 568 or Enterococcus faecium. At the time, this microbial risk assessment had the advantage of being 569 quantitative and thus more transparent when compared to previous assessments focusing on 570 AMR. Thus, the authors highlighted several limitations, particularly with regards to data gaps on 571 the probability of treatment failure due to the antimicrobial resistant bacteria and the probability 572 of resistant determinant development. In contrast to many evidence and risk assessments 573 conducted elsewhere, the results of this study lead the authors to conclude that current use of 
574 macrolides in cattle, poultry, and swine create a risk much lower than the potential benefit to food 575 safety, animal welfare, and public health (87).

576 The same author published another risk assessment a few years later, applying a similar approach

577 to estimate the risk of a different combination of antimicrobial-pathogen - fluoroquinolone-

578 resistant Salmonella and Campylobacter in beef in the US (88). This approach was able to

579 provide a better measure of uncertainty but was similar in its findings, concluding that the risk of

580 health consequences in humans was minimal.

581 The most recent quantitative risk assessment study published is also the more novel and

582 promising of the AMR studies here reviewed (89). It considered the existence of environmental

583 compartments resulting from sewage-treatment plants, agriculture production and manufacturing

584 industries, and assessed their role in the maintenance, emergence and possible dissemination of

585 antibiotic resistance. This study used probabilistic methods to assess the risks of antibiotic

586 resistance development and neutralizing antibiotic pressures in hotspot environments.

587 Importantly, this study presents a modelling approach to assess the selective pressure exerted by

588 antibiotics in bacterial communities and to calculate antibiotic resistance development risks.

589 While the described approach was exemplarily used to model antibiotic resistance risks in an

590 intensive aquaculture production scenario of south-east Asia, it has potential to be applied to

591 other cases, including other types of animal production, settings and drugs.

\section{$592 \quad$ 3.4. Strength and weaknesses}

593 Microbial risk assessment is a science-based tool with proven benefits in supporting food safety 594 authorities in policy making. It is hence aspired to continue its use in assessing the consequences 595 for the consumer of the transmission of AMR genes /pathogens throughput the food chain. The 
fact that it is a well-defined, stepwise-structured method facilitates its adaptation to the food

597 safety challenge of AMR. However, several limitations have already been identified and require 598 the joint focus of the scientific community, risk assessors and authorities. Examples of a few 599 critical challenges are:

600 - The definition of antimicrobial resistance is critical for the four steps of microbial risk 601 assessment, and needs therefore to be well-established at the very start of a risk assessment 602 study. Martínez et al. (2014) (75) explains the existence of several possible definitions of 603 resistance, (namely clinical, epidemiological and operational), and two definitions of 604 resistance gene (ecological and operational). The adoption of standard concepts and 605 terminology is a requisite for the transparency of microbial risk assessment and an important 606 part of its development. Although transmission of AMR genes and antimicrobial resistant 607 bacteria may be perceived and have been defined as two separate hazards, it has also been 608 recently suggested that the risk of AMR transmission to humans cannot be estimated unless 609 the AMR gene pool and the presence and quantity of antimicrobial resistant bacteria that are able to colonize and multiply in the human body are both taken into consideration (69).

614 the microbial population (and corresponding AMR genes) may significantly change between 615 "farm" and "fork" (90, 91). Consequently, microbial risk assessment for AMR is highly dependent on data collected at several points of the transmission pathway, both from the source(s) of AMR and from exposed human subjects. 
- While new generation sequencing attractively provides a broad characterization of the

619 presence and abundance of AMR genes in a particular pathogen or in the microbiome from a

620 particular reservoir, it remains a challenge to determine variability of the resistome and of the

621 potential to exchange AMR genes (i.e. presence of phage recombination sites, plasmids,

622 integrons or transposons) between different pathogen strains (69). This knowledge is crucial,

623 respectively, to assign the AMR genes detected with metagenomics to the corresponding

624 bacterial hosts, and to account for the occurrence of horizontal gene transfer between

625 commensal and pathogenic bacteria in a population.

626 - Furthermore, an important challenge for the integration of metagenomics data in MRA is the

627 harmonization of languages between the "omics" and the food microbiology communities

$628 \quad(92)$.

629 - Risk characterization requires knowledge of the relationship between a "dose", resulting from

630 exposure assessment, and a "response", i.e. the adverse health effect of exposure. However,

631 the infective dose and the modes of transmission of most of the antimicrobial resistant

632 bacteria of relevance are still unknown (69), which represents an important knowledge gap

633 for the development of microbial risk assessment for antimicrobial resistance.

634 - Finally, a major limitation of the current microbial risk assessment frameworks is that they do 635 not allow estimating the long-term impact of exposure to AMR. Particularly serious public 636 health consequences of AMR arise when multiresistant bacteria emerge and become widely

637 spread. There is therefore the need to develop microbial risk assessment methods that include

638 a different characterization of the risk of AMR. In addition to immediate consequences to

639 human health due to a single exposure to a antimicrobial resistant pathogen, it is necessary to

640 estimate the likelihood that such exposure (eventually together with past and subsequent 
ones, to the same or other types of AMR) will lead to the development of antimicrobial multiresistance in the future. Also, it is necessary to assess the potential of multi-resistance spread, to characterize the severity of the consequences of exposure to multi-resistance and to estimate the time from initial exposure to those consequences.

647 Several position and stakeholder papers have stressed the need for improved quality and 648 increased amount of data for risk assessment of AMR (see. e.g.(93)). These include e.g. data on 649 antimicrobial use in animal production, AMR surveillance data in animals, foods and humans, 650 and gene transfer and spread of AMR genes. All data requirements apply for most source 651 attribution studies, and thus are transversal to the methods described in this chapter. Likewise, 652 many of the challenges to the application of these methods in the context of AMR are common to 653 source attribution and risk assessment approaches (Table 1).

654 Table 1. Definition, overview of methods and main challenges of source attribution and microbial 655 risk assessment approaches.

\section{Source attribution Microbial risk assessment}

\begin{tabular}{|c|c|c|}
\hline \multirow[t]{4}{*}{ Definition } & Partitioning of human cases & Systematic and science-based approach \\
\hline & of illness to the responsible & to estimate the risk of microbial \\
\hline & sources (e.g. foods, animal & hazards in the production-to- \\
\hline & reservoirs) & consumption chain \\
\hline
\end{tabular}

Methods

- Microbial subtyping

- Qualitative RA* 
- Comparative

exposure assessment

- Outbreak-data

analysis

- Case-control studies

- Expert elicitations

- Intervention studies
- Semi-quantitative RA

- Quantitative RA

- Deterministic

○ Probabilistic

\section{Main challenges in the} context of AMR
- Hazard identification, e.g. the antimicrobial drug, the antimicrobial resistant pathogen or the AMR determinant

- Lack of occurrence/prevalence data

- Definition of the health outcome, i.e. infection with antimicrobial resistant agent, treatment failure (in case treatment is needed) or spread of resistance determinant between commensal and pathogenic organisms

- Lack of epidemiological data
- Establishment of dose-response relationship

- Determining variability of the resistome and of the potential to exchange AMR genes between different pathogen strains

*RA: risk assessment 
658 The studies here described all show the importance of knowledge on 1) the most important 659 sources and routes of transmission of antimicrobial resistant bacteria or AMR genes, 2) the 660 actual risk for human health, and 3) the points in the transmission chain where interventions 661 could be effective to reduce this risk. While all findings so far have been crucial to direct policies 662 and raise awareness to the public health impact of AMR in animals and foods, they are 663 insufficient for a complete understanding of the underlying transmission mechanisms and the real 664 impact of AMR. Several challenges have been addressed, including the fact that emergence and 665 spread of AMR is complex. From an epidemiological point of view, the risk of AMR most 666 probably follows the "sufficient-component causes" principle (94). The sufficient-component 667 causes is an epidemiological causal modeling approach that can be used to explain diseases, or 668 conditions like AMR, characterized by many causes, none of which alone is necessary or 669 sufficient. The relations among the causes are described in a way that a sufficient cause is a set of 670 minimal conditions that will definitely lead to the outcome (e.g. antimicrobial resistant infection), 671 and a component cause is one of the minimal conditions included in a sufficient cause (94). For 672 example, a particular resistance gene can be a component cause of an antimicrobial resistant 673 infection, but the sufficient cause of the latter includes other conditions, such as the bacterial 674 strain carrying that particular gene, that pathogen causing infection, treatment of the infection 675 with antimicrobial(s) for which resistance is encoded in the gene, and actual expression of that 676 resistance gene. The future of microbial risk assessment for antimicrobial resistance may

677 therefore include defining the components sufficient to cause AMR transmission from 678 animals/foods/environment to humans followed by treatment failure of infections by 679 antimicrobial resistant pathogens. 
680 Recent developments in "omics" technologies (whole genome sequencing and metagenomics, 681 transcriptomics, proteomics, metabolomics, fluxomics) provide unique opportunities to fill in 682 some of our knowledge gaps. It is now widely recognized that these "omics" technologies have 683 advantages compared to traditional phenotypic culture-based methods for characterizing 684 microorganisms $(92,95)$.

685 Brul et al (2012)(92) described in detail how "omics" can be integrated in each step of microbial 686 risk assessment, contributing to a mechanistic insight into the interaction between 687 microorganisms and their hosts, new perspectives on strain diversity and variability and 688 physiological uncertainty, and overall more robust risk assessments. Den Besten et al. (2017)(95) 689 discussed the utility of "omics" technologies applied by the food industry, to help identify the 690 influence of different bacterial ecosystems on both pathogen survival and growth - information 691 that can eventually contribute to the future definition of Food Safety Objectives (FSO).

692 A particular advantage of metagenomics is that it provides a picture of the whole microbial 693 community and its resistome, which is key to understanding AMR emergence and spread in a 694 population. Importantly, these new "typing" techniques have been rapidly followed by new 695 bioinformatics and new statistics/modelling tools that allow for the analysis and sense-making of 696 such (big) data $(92,96)$. For example, machine learning has the potential to be applied on the 697 analysis of omics data. Combining machine learning approaches with metagenomics and farm 698 specific data could allow for describing e.g. health, production efficiency, and the relative 699 abundance of AMR genes, based on the identification of (clusters of) genetic factors in the farm 700 microbiome. In addition, such techniques could be used to examine the predictive importance of 701 (clusters of) genetic factors in order to characterize 1) a 'healthy farm microbiome' or 2) AMR 702 genes in a specific animal reservoir. They can also be used to identify (combinations of) specific 
703 husbandry practices that are associated with e.g. a particular resistome or a 'healthy farm

704 microbiome'. The latter could lead to recommendations on how to shift the farm microbiome in

705 order to improve the overall health of the farm, and consequently on the long term, to reduce the

706 level of antimicrobial use and antimicrobial resistant bacteria. It is possible that promoting a

707 'healthy farm microbiome' will have a more long-term impact on the overall reduction of AMR,

708 than focusing exclusively on the farm resistome. Metagenomics and other "omics" technologies

709 have hence enormous potential for the future development of source attribution and microbial

710 risk assessment of AMR through foods. To explore their full potential, different technologies

711 shall be combined. For example, genomics studies should be coupled with proteomics, as gene-

712 expression studies do not always reflect the actual protein levels (92). Also, genomic similarities

713 may not imply similarities in behavior, as the surrounding environment (food matrix, bacterial

714 ecosystem, etc) also plays a role (95) . Furthermore, "omics" data are not sufficient without

715 accompanying epidemiological data that allow for the identification of risk factors for AMR.

\section{5. Concluding remarks}

717 Recent developments in source-attribution and microbial risk assessment of AMR are promising

718 and have significantly contributed to the evolution of each of these methods. However, the

719 adaptation to the "omics" big data era is happening at a much slower pace than the speed at

720 which these data are becoming available. This is due to the many challenges encountered when

721 interpreting those data.

722 Antimicrobial resistance at the animal reservoir, food, environment and human levels is

723 increasingly described by the characterization of the resistomes of single bacteria isolates (by

724 whole genome sequencing) or the bacterial whole community (by metagenomics) representing

725 each of those populations. Gradually, AMR surveillance will convert from phenotypic to 
726 genotypic (e.g. PulseNet International is already on its way to standardize whole genome

727 sequencing-based subtyping of foodborne disease (96). For a successful transition, it is crucial to

728 pair genomic data with phenotypic data and relevant explanatory epidemiological data.

729 This transition will require a parallel adaptation of the existing analysis methods, which will 730 include the development of new source-attribution and microbial risk assessment modelling

731 approaches. It is therefore with great expectation that we foresee in the near future a surge of

732 influencing and inspiring scientific output in both fields.

733 6. References

734 1. Pires SM, Evers EG, Van Pelt W, Ayers T, Scallan E, Angulo FJ, Havelaar A, Hald T, Schroeter A,

735 Brisabois A, Thebault A, Käsbohrer A, Schroeder C, Frank C, Guo C, Wong DLF, Döpfer D, Snary E,

736 Nichols G, Spitznagel H, Wahlström H, David J, Pancer K, Stark K, Forshell LP, Nally P, Sanders P,

737 Hiller P. 2009. Attributing the human disease burden of foodborne infections to specific sources.

$738 \quad$ Foodborne Pathog Dis 6.

739 2. Mullner P, Jones G, Noble A, Spencer SEF, Hathaway S, French NP. 2009. Source attribution of

740 food-borne zoonoses in New Zealand: A modified hald model. Risk Anal 29:970-984.

741 3. Hald T, Vose D, Wegener HC, Koupeev T. 2004. A Bayesian Approach to Quantify the Contribution 742 of Animal-Food Sources to Human Sahnonellosis. Risk Anal 24:255-269.

743 4. De Knegt LV, Pires SM, Hald T. 2015. Using surveillance and monitoring data of different origins in 744 a Salmonella source attribution model: A European Union example with challenges and proposed 745 solutions. Epidemiol Infect 143.

746 5. Pires SM, Vigre H, Makela P, Hald T. 2010. Using outbreak data for source attribution of human 747 salmonellosis and campylobacteriosis in Europe. Foodborne Pathog Dis 7. 
748 6. Guo C, Hoekstra RM, Schroeder CM, Pires SM, Ong KL, Hartnett E, Naugle A, Harman J, Bennett P, 749 Cieslak P, Scallan E, Rose B, Holt KG, Kissler B, Mbandi E, Roodsari R, Angulo FJ, Cole D. 2011.

750 Application of Bayesian techniques to model the burden of human salmonellosis attributable to

751 U.S. food commodities at the point of processing: Adaptation of a Danish model. Foodborne

$752 \quad$ Pathog Dis 8.

753 7. Pires SM, Evers EG, van Pelt W, Ayers T, Scallan E, Angulo FJ, Havelaar A, Hald T. 2009. Attributing 754 the human disease burden of foodborne infections to specific sources. Foodborne Pathog Dis $755 \quad 6: 417-424$.

756 8. FAO. 1999. Principles and Guidelines for the Conduct of Microbiological Risk Assessment.

757 9. OIE. 2002. International Animal Health Code. Off Int des Epizoot Paris 23-30.

758

10. USDA. 2012. MICROBIAL RISK ASSESSMENT GUIDELINE PATHOGENIC MICROORGANISMS WITH FOCUS ON FOOD AND WATER Prepared by the Interagency Microbiological Risk Assessment Guideline Workgroup Microbial Risk Assessment Guideline.

761 11. Wegener HC. 2010. Danish initiatives to improve the safety of meat products. Meat Sci 84:276283.

12. Snary EL, Swart AN, Hald T. 2016. Quantitative Microbiological Risk Assessment and Source 764 Attribution for Salmonella : Taking it Further. Risk Anal 36:433-436.

13. Lester CH, Frimodt-Moller N, Sorensen TL, Monnet DL, Hammerum AM. 2006. In Vivo Transfer of the vanA Resistance Gene from an Enterococcus faecium Isolate of Animal Origin to an E. faecium Isolate of Human Origin in the Intestines of Human Volunteers. Antimicrob Agents Chemother 768 50:596-599.

14. Aarestrup FM. 2015. The livestock reservoir for antimicrobial resistance: a personal view on 

Biol Sci 370:20140085.

772 15. Hald T, Lo Fo Wong DM a, Aarestrup FM. 2007. The attribution of human infections with antimicrobial resistant Salmonella bacteria in Denmark to sources of animal origin. Foodborne

16. Vieira AR, Grass J, Fedorka-Cray PJ, Plumblee JR, Tate H, Cole DJ. 2016. Attribution of Salmonella enterica serotype Hadar infections using antimicrobial resistance data from two points in the food supply system. Epidemiol Infect 144:1983-1990.

778 17. Evers EG, Pielaat A, Smid JH, van Duijkeren E, Vennemann FBC, Wijnands LM, Chardon JE. 2017. Comparative Exposure Assessment of ESBL-Producing Escherichia coli through Meat Consumption. PLoS One 12:e0169589.

18. Barco L, Barrucci F, Olsen JE, Ricci A. 2013. Salmonella source attribution based on microbial subtyping. Int J Food Microbiol 163:193-203.

19. Mughini-Gras L, Barrucci F, Smid JH, Graziani C, Luzzi I, Ricci A, Barco L, Rosmini R, Havelaar AH, VAN Pelt W, Busani L. 2014. Attribution of human Salmonella infections to animal and food sources in Italy (2002-2010): adaptations of the Dutch and modified Hald source attribution models. Epidemiol Infect 142:1070-82.

20. Wilson DJ, Gabriel E, Leatherbarrow AJH, Cheesbrough J, Gee S, Bolton E, Fox A, Fearnhead P, Hart CA, Diggle PJ. 2008. Tracing the source of campylobacteriosis. PLoS Genet 4.

789 21. Pires SM, Vieira AR, Hald T, Cole D. 2014. Source Attribution of Human Salmonellosis: An 790 Overview of Methods and Estimates. Foodborne Pathog Dis 0:1-10.

791 22. de Knegt LV, Pires SM, Löfström C, Sørensen G, Pedersen K, Torpdahl M, Nielsen EM, Hald T. 
2016. Application of Molecular Typing Results in Source Attribution Models: The Case of Multiple Locus Variable Number Tandem Repeat Analysis (MLVA) of Salmonella Isolates Obtained from Integrated Surveillance in Denmark. Risk Anal 36.

23. Boysen L, Rosenquist H, Larsson JT, Nielsen EM, Sørensen G, Nordentoft S, Hald T. 2013. Source attribution of human campylobacteriosis in Denmark. Epidemiol Infect 1-10.

24. Mullner P, Spencer SEF, Wilson DJ, Jones G, Noble AD, Midwinter AC, Collins-Emerson JM, Carter P, Hathaway S, French NP. 2009. Assigning the source of human campylobacteriosis in New Zealand: A comparative genetic and epidemiological approach. Infect Genet Evol 9:1311-1319.

25. Little CL, Pires SM, Gillespie IA, Grant K, Nichols GL. 2010. Attribution of human Listeria monocytogenes infections in England and Wales to ready-to-eat food sources placed on the market: adaptation of the Hald Salmonella source attribution model. Foodborne Pathog Dis 7:749-756.

26. Mughini-Gras L, van Pelt W, van der Voort M, Heck M, Friesema I, Franz E. 2017. Attribution of human infections with Shiga toxin-producing Escherichia coli (STEC) to livestock sources and identification of source-specific risk factors, The Netherlands (2010-2014). Zoonoses Public Health.

27. Evers EG, Fels-Klerx HJ Van Der, Nauta MJ, Schijven JF, Havelaar AH. 2008. Campylobacter source attribution by exposure assessment. Int J Risk Assess Manag.

810 28. Kosmider RD, Nally P, Simons RRL, Brouwer A, Cheung S, Snary EL, Wooldridge M. 2010. Attribution of human VTEC 0157 infection from meat products: A quantitative risk assessment approach. Risk Anal 30:753-765. 

114.

30. FDA. 2003. Quantitative Assessment of Relative Risk to Public Health From Foodborne Listeria monocytogenes Among Selected Categories of Ready-to-Eat Foods SUMMARY OF PUBLIC COMMENTS AND FDA/FSIS REVISIONS TO RISK ASSESSMENT.

819 31. EFSA. 2009. SCIENTIFIC OPINION Cadmium in food Scientific Opinion of the Panel on Contaminants in the Food Chain. EFSA J 980:1-139.

32. EFSA. 2010. Scientific Opinion on Lead in Food. EFSA J 8:1570.

33. Cassini A, Hathaway S, Havelaar A, Koopmans M, Koutsoumanis K, Messens W, Müller-Seitz G, Nørrung B, Rizzi V, Scheutz F. 2016. Microbiological risk assessment. EFSA J 14:1-10.

34. EFSA. 2007. Opinion of the scientific panel on contaminants in the food chain [CONTAM] related to the potential increase of consumer health risk by a possible increase of the existing maximum levels for aflatoxins in almonds, hazelnuts and pistachios and derived prod. EFSA J 5:446.

35. Carmo LP, Nielsen LR, da Costa PM, Alban L. 2014. Exposure assessment of extended-spectrum beta-lactamases/AmpC beta-lactamases-producing Escherichia coli in meat in Denmark. Infect

36. Olsen SJ, MacKinnon LC, Goulding JS, Bean NH, Slutsker L. 2000. Surveillance for foodbornedisease outbreaks--United States, 1993-1997. MMWR CDC Surveill Summ Morb Mortal Wkly report CDC Surveill Summ 49:1-62.

833 37. Anonymous. EUR-Lex - 32003L0099 - EN. Off J L 325 , 12/12/2003 P 0031 - 0040; OPOCE.

834 38. Neimann J, Engberg J, Mølbak K, Wegener HC. 2003. A case-control study of risk factors for 835 sporadic campylobacter infections in Denmark. Epidemiol Infect 130:353-66. 
39. Painter J a, Ayers T, Woodruff R, Blanton E, Perez N, Hoekstra RM, Griffin PM, Braden C. 2009. Recipes for foodborne outbreaks: a scheme for categorizing and grouping implicated foods. Foodborne Pathog Dis 6:1259-1264.

40. Pires SM, Vigre H, Makela P, Hald T. 2010. Using outbreak data for source attribution of human salmonellosis and campylobacteriosis in Europe. Foodborne Pathog Dis 7:1351-1361.

41. Painter JA, Hoekstra RM, Ayers T, Tauxe R V., Braden CR, Angulo FJ, Griffin PM. 2013. Attribution of foodborne illnesses, hospitalizations, and deaths to food commodities by using outbreak data, United States, 1998-2008. Emerg Infect Dis 19:407-415.

42. Pires SM, Vieira AR, Perez E, Wong DLF, Hald T. 2012. Attributing human foodborne illness to food sources and water in Latin America and the Caribbean using data from outbreak investigations. Int J Food Microbiol 152:129-138.

43. Ravel a, Greig J, Tinga C, Todd E, Campbell G, Cassidy M, Marshall B, Pollari F. 2009. Exploring historical Canadian foodborne outbreak data sets for human illness attribution. J Food Prot 72:1963-76.

44. King N, Lake R, Campbell D. 2011. Source attribution of nontyphoid salmonellosis in new zealand using outbreak surveillance data. J Food Prot 74:438-45.

45. Jones TF, Kellum ME, Porter SS, Bell M, Schaffner W. 2002. An outbreak of community-acquired foodborne illness caused by methicillin-resistant Staphylococcus aureus. Emerg Infect Dis 8:8284.

46. Mølbak K, Baggesen DL, Aarestrup FM, Ebbesen JM, Engberg J, Frydendahl K, Gerner-Smidt P, Petersen AM, Wegener HC. 1999. An Outbreak of Multidrug-Resistant, Quinolone-Resistant Salmonella enterica Serotype Typhimurium DT104. N Engl J Med 341:1420-1425. 
47. BROWN AC, GRASS JE, RICHARDSON LC, NISLER AL, BICKNESE AS, GOULD LH. 2017. Antimicrobial resistance in Salmonella that caused foodborne disease outbreaks: United States, 2003-2012. Epidemiol Infect 145:766-774.

48. Engberg J. 2006. Contributions to the epidemiology of Campylobacter infections. A review of clinical and microbiological studies. Dan Med Bull 53:361-89.

49. Domingues a. R, Pires SM, Halasa T, Hald T. 2012. Source attribution of human campylobacteriosis using a meta-analysis of case-control studies of sporadic infections. Epidemiol Infect 140:970-981.

50. Pires SM. 2013. Assessing the applicability of currently available methods for attributing foodborne disease to sources, including food and food commodities. Foodborne Pathog Dis 10:206-13.

51. Varma JK, Marcus R, Stenzel SA, Hanna SS, Gettner S, Anderson BJ, Hayes T, Shiferaw B, Crume TL, Joyce K, Fullerton KE, Voetsch AC, Angulo FJ. 2006. Highly Resistant Salmonella NewportMDRAmpC Transmitted through the Domestic US Food Supply: A FoodNet Case-Control Study of Sporadic Salmonella Newport Infections, 2002-2003. J Infect Dis 194:222-230.

52. Kassenborg HD, Smith KE, Vugia DJ, Rabatsky-Ehr T, Bates MR, Carter MA, Dumas NB, Cassidy MP, Marano N, Tauxe RV, Angulo FJ. 2004. Fluoroquinolone-Resistant Campylobacter Infections: Eating Poultry Outside of the Home and Foreign Travel Are Risk Factors. Clin Infect Dis 38:S279S284.

53. Havelaar AH, Galindo AV, Kurowicka D, Cooke RM. 2008. Attribution of foodborne pathogens using structured expert elicitation. Foodborne Pathog Dis 5:649-659.

54. Ravel A, Davidson VJ, Ruzante JM, Fazil A. 2010. Foodborne proportion of gastrointestinal illness: 
55. Hald T, Aspinall W, Devleesschauwer B, Cooke R, Corrigan T, Havelaar AH, Gibb HJ, Torgerson PR, Kirk MD, Angulo FJ, Lake RJ, Speybroeck N, Hoffmann S. 2016. World Health Organization estimates of the relative contributions of food to the burden of disease due to selected foodborne hazards: A structured expert elicitation. PLoS One 11:1-35.

56. Cooke R. 1991. Experts in uncertainty : opinion and subjective probability in science. Oxford University Press.

57. Anonymous. 2017. Annual Report on Zoonoses in Denmark 2016. Natl Food Institute, Tech Univ Denmark.

58. Kim H, Kim YA, Park YS, Choi MH, Lee GI, Lee K. 2017. Risk Factors and Molecular Features of Sequence Type (ST) 131 Extended-spectrum $\beta$-Lactamase-producing Escherichia coli in Community-onset Bacteremia. Sci Rep 7:14640.

59. Vos T, Barber RM, Bell B, Bertozzi-Villa A, Biryukov S, Bolliger I, Charlson F, Davis A, Degenhardt L, Dicker D, Duan L, Erskine H, Feigin VL, Ferrari AJ, Fitzmaurice C, Fleming T, Graetz N, Guinovart C, Haagsma J, Hansen GM, Hanson SW, Heuton KR, Higashi H, Kassebaum N, Kyu H, Laurie E, Liang X, Lofgren K, Lozano R, MacIntyre MF, Moradi-Lakeh M, Naghavi M, Nguyen G, Odell S, Ortblad K, Roberts DA, Roth GA, Sandar L, Serina PT, Stanaway JD, Steiner C, Thomas B, Vollset SE, Rmeileh NME, Aburto TC, Achoki T, Ackerman IN, Adelekan A, Ademi Z, Adou AK, Adsuar JC, Arnlov J, Agardh EE, Al Khabouri MJ, Alam SS, Alasfoor D, Albittar MI, Alegretti MA, Aleman A V., Alemu ZA, Alfonso-Cristancho R, Alhabib S, Ali R, Alla F, Allebeck P, Allen PJ, AlMazroa MA, Alsharif U, Alvarez E, Alvis-Guzman N, Ameli O, Amini H, Ammar W, Anderson BO, Anderson HR, 
Antonio CAT, Anwari P, Apfel H, Arsenijevic VSA, Artaman A, Asghar RJ, Assadi R, Atkins LS, Atkinson C, Badawi A, Bahit MC, Bakfalouni T, Balakrishnan K, Balalla S, Banerjee A, Barker-Collo SL, Barquera S, Barregard L, Barrero LH, Basu S, Basu A, Baxter A, Beardsley J, Bedi N, Beghi E, Bekele T, Bell ML, Benjet C, Bennett DA, Bensenor IM, Benzian H, Bernabe E, Beyene TJ, Bhala N, Bhalla A, Bhutta Z, Bienhoff K, Bikbov B, Abdulhak A Bin, Blore JD, Blyth FM, Bohensky MA, Basara BB, Borges G, Bornstein NM, Bose D, Boufous S, Bourne RR, Boyers LN, Brainin M, Brauer M, Brayne CEG, Brazinova A, Breitborde NJK, Brenner H, Briggs ADM, Brooks PM, Brown J, Brugha TS, Buchbinder R, Buckle GC, Bukhman G, Bulloch AG, Burch M, Burnett R, Cardenas R, Cabral NL, Campos-Nonato IR, Campuzano JC, Carapetis JR, Carpenter DO, Caso V, Castaneda-Orjuela CA, Catala-Lopez F, Chadha VK, Chang JC, Chen H, Chen W, Chiang PP, Chimed-Ochir O, Chowdhury R, Christensen H, Christophi CA, Chugh SS, Cirillo M, Coggeshall M, Cohen A, Colistro V, Colquhoun SM, Contreras AG, Cooper LT, Cooper C, Cooperrider K, Coresh J, Cortinovis M, Criqui MH, Crump JA, Cuevas-Nasu L, Dandona R, Dandona L, Dansereau E, Dantes HG, Dargan PI, Davey G, Davitoiu D V., Dayama A, De La Cruz-Gongora V, De La Vega SF, De Leo D, Del Pozo-Cruz B, Dellavalle RP, Deribe K, Derrett S, Des Jarlais DC, Dessalegn M, DeVeber GA, Dharmaratne SD, Diaz-Torne C, Ding EL, Dokova K, Dorsey ER, Driscoll TR, Duber H, Durrani AM, Edmond KM, Ellenbogen RG, Endres M, Ermakov SP, Eshrati B, Esteghamati A, Estep K, Fahimi S, Farzadfar F, Fay DFJ, Felson DT, Fereshtehnejad SM, Fernandes JG, Ferri CP, Flaxman A, Foigt N, Foreman KJ, Fowkes FGR, Franklin RC, Furst T, Futran ND, Gabbe BJ, Gankpe FG, Garcia-Guerra FA, Geleijnse JM, Gessner BD, Gibney KB, Gillum RF, Ginawi IA, Giroud M, Giussani G, Goenka S, Goginashvili K, Gona P, De Cosio TG, Gosselin RA, Gotay CC, Goto A, Gouda HN, Guerrant RL, Gugnani HC, Gunnell D, Gupta M, Hankey GJ, Hao Y, Harb HL, Haro JM, Havmoeller R, Hay RJ, Hay S, Hedayati MT, Pi IBH, Heydarpour P, Hijar M, Hoek HW, Hoffman HJ, Hornberger JC, Hosgood HD, Hossain M, Hotez PJ, 
Hoy DG, Hsairi M, Hu H, Hu G, Huang JJ, Huang C, Huiart L, Husseini A, lannarone M, Iburg KM, Innos K, Inoue M, Jacobsen KH, Jassal SK, Jeemon P, Jensen PN, Jha V, Jiang G, Jiang Y, Jonas JB, Joseph J, Juel K, Kan H, Karch A, Karimkhani C, Karthikeyan G, Katz R, Kaul A, Kawakami N, Kazi DS, Kemp AH, Kengne AP, Khader YS, Khalifa SEAH, Khan EA, Khan G, Khang YH, Khonelidze I, Kieling C, Kim D, Kim S, Kimokoti RW, Kinfu Y, Kinge JM, Kissela BM, Kivipelto M, Knibbs L, Knudsen AK, Kokubo Y, Kosen S, Kramer A, Kravchenko M, Krishnamurthi R V., Krishnaswami S, Defo BK, Bicer BK, Kuipers EJ, Kulkarni VS, Kumar K, Kumar GA, Kwan GF, Lai T, Lalloo R, Lam H, Lan Q, Lansingh VC, Larson H, Larsson A, Lawrynowicz AEB, Leasher JL, Lee JT, Leigh J, Leung R, Levi M, Li B, Li Y, Li Y, Liang J, Lim S, Lin HH, Lind M, Lindsay MP, Lipshultz SE, Liu S, Lloyd BK, Ohno SL, Logroscino G, Looker KJ, Lopez AD, Lopez-Olmedo N, Lortet-Tieulent J, Lotufo PA, Low N, Lucas RM, Lunevicius LM, Margono C, Marks GB, Marzan MB, Masci JR, Mason-Jones AJ, Matzopoulos RG, Mayosi BM, Mazorodze TT, McGill NW, McGrath JJ, McKee M, McLain A, McMahon BJ, Meaney PA, Mehndiratta MM, Mejia-Rodriguez F, Mekonnen W, Melaku YA, Meltzer M, Memish ZA, Mensah G, Meretoja A, Mhimbira FA, Micha R, Miller TR, Mills EJ, Mitchell PB, Mock CN, Moffitt TE, Ibrahim NM, Mohammad KA, Mokdad AH, Mola GL, Monasta L, Montico M, Montine TJ, Moore AR, Moran AE, Morawska L, Mori R, Moschandreas J, Moturi WN, Moyer M, Mozaffarian D, Mueller UO, Mukaigawara M, Murdoch ME, Murray J, Murthy KS, Naghavi P, Nahas Z, Naheed A, Naidoo KS, Naldi L, Nand D, Nangia V, Narayan KMV, Nash D, Nejjari C, Neupane SP, Newman LM, Newton CR, Ng M, Ngalesoni FN, Nhung NT, Nisar MI, Nolte S, Norheim OF, Norman RE, Norrving B, Nyakarahuka L, Oh IH, Ohkubo T, Omer SB, Opio JN, Ortiz A, Pandian JD, Panelo CIA, 
Sabin N, Sacco RL, Ksoreide K, Saha S, Sahathevan R, Sahraian MA, Sampson U, Sanabria JR,

Sanchez-Riera L, Santos IS, Satpathy M, Saunders JE, Sawhney M, Saylan MI, Scarborough P,

Shi P, Shibuya K, Shinohara Y, Shiri R, Shishani K, Shiue I, Shrime MG, Sigfusdottir ID, Silberberg

DH, Simard EP, Sindi S, Singh JA, Singh L, Skirbekk V, Sliwa K, Soljak M, Soneji S, Soshnikov SS, 
lived with disability for 301 acute and chronic diseases and injuries in 188 countries, 1990-2013: A systematic analysis for the Global Burden of Disease Study 2013. Lancet 386:743-800.

60. HARB A, O'DEA M, HANAN ZK, ABRAHAM S, HABIB I. 2017. Prevalence, risk factors and antimicrobial resistance of Salmonella diarrhoeal infection among children in Thi-Qar Governorate, Iraq. Epidemiol Infect 1-11.

61. Loman NJ, Constantinidou C, Christner M, Rohde H, Chan JZ-M, Quick J, Weir JC, Quince C, Smith GP, Betley JR, Aepfelbacher M, Pallen MJ. 2013. A Culture-Independent Sequence-Based Metagenomics Approach to the Investigation of an Outbreak of Shiga-Toxigenic Escherichia coli O104:H4. JAMA 309:1502.

62. Aarestrup FM, Seyfarth AM, Emborg HD, Pedersen K, Hendriksen RS, Bager F. 2001. Effect of abolishment of the use of antimicrobial agents for growth promotion on occurrence of antimicrobial resistance in fecal enterococci from food animals in Denmark. Antimicrob Agents Chemother 45:2054-9.

63. Jensen V, de Knegt LV, Andersen, VD WA. 2014. Temporal relationship between decrease in antimicrobial prescription for Danish pigs and the "Yellow Card" legal intervention directed at reduction of antimicrobial use. Prev Vet Med 117:554-564.

64. Agers $\varnothing$ Y, Aarestrup FM. 2013. Voluntary ban on cephalosporin use in Danish pig production has effectively reduced extended-spectrum cephalosporinase-producing Escherichia coli in slaughter pigs. J Antimicrob Chemother 68:569-572.

65. OIE. 2002. Qualitative and quantitative risk assessment for human salmonellosis due to multiresistant Salmonella Typhimurium DT104 from consumption of Danish dry-cured pork sausages. Prev Vet Med 52:251-265. 
997 66. Claycamp HG, Hooberman BH. 2004. Antimicrobial Resistance Risk Assessment in Food Safety. J

$998 \quad$ Food Prot 67:2063-2071.

999 67. Snary EL, Kelly LA, Davison HC, Teale CJ, Wooldridge M. 2004. Antimicrobial resistance: a

1000 microbial risk assessment perspective. J Antimicrob Chemother 53:906-17.

1001 68. Salisbury JG, Nicholls TJ, Lammerding AM, Turnidge J, Nunn MJ. A risk analysis framework for the 1002 long-term management of antibiotic resistance in food-producing animals.

1003

1004

1005

1006

1007

1008

1009

1010

1011

1012

1013

1014

1015

1016

1017

69. Manaia CM. 2017. Assessing the Risk of Antibiotic Resistance Transmission from the Environment to Humans: Non-Direct Proportionality between Abundance and Risk. Trends Microbiol 25:173181.

70. Bezoen A, Van Haren W, Hanekamp JC. Emergence of a Debate: AGPs and Public Health.

71. WHO. 2016. Critically Important Antimicrobials for Human Medicine, 5th Revision.

72. Collineau L, Carmo LP, Endimiani A, Magouras I, Müntener C, Schüpbach-Regula G, Stärk KDC. 2017. Risk Ranking of Antimicrobial-Resistant Hazards Found in Meat in Switzerland. Risk Anal.

73. Bartholomew MJ, Vose DJ, Tollefson LR, Travis CC. 2005. A Linear Model for Managing the Risk of Antimicrobial Resistance Originating in Food Animals. Risk Anal 25:99-108.

74. CVMP. 2013. Guideline on the assessment of the risk to public health from antimicrobial resistance due to the use of an antimicrobial VMPs in food-producing animals.

75. Martínez JL, Coque TM, Baquero F. 2014. What is a resistance gene? Ranking risk in resistomes. Nat Rev Microbiol 13:116-123.

76. Buchanan RL, Smith JL, Long W. 2000. Microbial risk assessment: dose-response relations and risk characterization. Int J Food Microbiol 58:159-72. 
1018

1019

1020

1021

1022

1023

1024

1025

1026

1027

1028

1029

1030

1031

1032

1033

1034

1035

1036

1037

1038

1039

77. Lammerding AM, Fazil A. 2000. Hazard identification and exposure assessment for microbial food safety risk assessment, p. 147-157. In International Journal of Food Microbiology. Elsevier.

78. Nauta MJ. 2008. The Modular Process Risk Model (MPRM): a Structured Approach to Food Chain Exposure Assessment, p. 99-136. In Microbial Risk Analysis of Foods. American Society of Microbiology.

79. Waltner-Toews D, McEwen SA. 1994. Residues of antibacterial and antiparasitic drugs in foods of animal origin: a risk assessment. Prev Vet Med 20:219-234.

80. Anonymous. 2014. MRSA risk assessment Prepared by the MRSA expert group.

81. Alban L, Ellis-Iversen J, Andreasen M, Dahl J, Sönksen UW. 2017. Assessment of the Risk to Public Health due to Use of Antimicrobials in Pigs-An Example of Pleuromutilins in Denmark. Front Vet Sci 4:74.

82. Alban L, Nielsen EO, Dahl J. 2008. A human health risk assessment for macrolide-resistant Campylobacter associated with the use of macrolides in Danish pig production. Prev Vet Med 83:115-129.

83. FDA. 2000. Human Health Impact of Fluoroquinolone Resistant Campylobacter Attributed to the Consumption of Chicken Food and Drug Administration Center for Veterinary Medicine.

84. Nelson JM, Chiller TM, Powers JH, Angulo FJ. 2007. Fluoroquinolone-Resistant Campylobacter Species and the Withdrawal of Fluoroquinolones from Use in Poultry: A Public Health Success Story. Clin Infect Dis 44:977-980.

85. Anderson SA, Woo RWY, Crawford LM. 2001. Risk assessment of the impact on human health of resistant Campylobacter jejuni from -uoroquinolone use in beef cattle. Food Cont 13-25.

86. FDA. 2003. Guidance for Industry \#152 - Evaluating the Safety of Antimicrobial New Animal Drugs 
with Regard to Their Microbiological Effects on Bacteria of Human Health Concern - October 23, 2003.

1042

1043

1044

1045

1046

1047

1048

1049

1050

1051

1052

1053

1054

1055

1056

1057

1058

1059

1060

1061

87. Hurd HS, Doores S, Hayes D, Mathew A, Maurer J, Silley P, Singer RS, Jones RN. 2004. Public Health Consequences of Macrolide Use in Food Animals: A Deterministic Risk Assessment. J Food Prot 67:980-992.

88. Hurd HS, Vaughn MB, Holtkamp D, Dickson J, Warnick L. Quantitative Risk from FluoroquinoloneResistant Salmonella and Campylobacter Due to Treatment of Dairy Heifers with Enrofloxacin for Bovine Respiratory Disease.

89. Andreu Rico, Rianne Jacobs, Paul J.Van den Brink A. 2017. A probabilistic approach to assess antibiotic resistance development risks in environmental compartments and its application to an intensive aquaculture production scenario. Environ Pollut 231:918-928.

90. Chaillou S, Chaulot-Talmon A, Caekebeke H, Cardinal M, Christieans S, Denis C, Hélène Desmonts M, Dousset X, Feurer C, Hamon E, Joffraud J-J, La Carbona S, Leroi F, Leroy S, Lorre S, Macé S, Pilet M-F, Prévost H, Rivollier M, Roux D, Talon R, Zagorec M, Champomier-Vergès M-C. 2015. Origin and ecological selection of core and food-specific bacterial communities associated with meat and seafood spoilage. ISME J 9:1105-1118.

91. De Filippis F, La Storia A, Villani F, Ercolini D. 2013. Exploring the Sources of Bacterial Spoilers in Beefsteaks by Culture-Independent High-Throughput Sequencing. PLoS One 8:e70222.

92. S.Brula, J. Bassettb, P. Cookc, S. Katharioud PMRJB. 2012. “Omics” technologies in quantitative microbial risk assessment. Trends Food Sci Technol 27:12-24.

93. Scott A.McEwen RSS. 2006. Stakeholder position paper: The need for antimicrobial use data for risk assessment. Prev Vet Med 73:169-176. 
1062 94. Madsen AM, Hodge SE, Ottman R. 2011. Causal models for investigating complex disease: I. A 1063 primer. Hum Hered 72:54-62.

1064 95. den Besten HMW, Amézquita A, Bover-Cid S, Dagnas S, Ellouze M, Guillou S, Nychas G, O’Mahony 1065 C, Pérez-Rodriguez F, Membré J-M. 2017. Next generation of microbiological risk assessment: Potential of omics data for exposure assessment. Int J Food Microbiol.

1067 96. Nadon C, Van Walle I, Gerner-Smidt P, Campos J, Chinen I, Concepcion-Acevedo J, Gilpin B, Smith 1068 AM, Kam KM, Perez E, Trees E, Kubota K, Takkinen J, Nielsen EM, Carleton H, FWD-NEXT Expert Panel. 2017. PulseNet International: Vision for the implementation of whole genome sequencing (WGS) for global food-borne disease surveillance. Eurosurveillance 22:30544. 